\title{
Inflation and Stock Prices: No Illusion
}

\author{
Chao Wei \\ George Washington University
}

October 24, 2006

\begin{abstract}
Campbell and Vuolteenaho (2004) use VAR results to advocate inflation illusion as the explanation for the positive association between inflation and the dividend yield. Contrary to their results, we find that a fully rational dynamic general equilibrium model can generate a positive correlation between the dividend yield and inflation of comparable size to its data counterpart. The model results support a proxy hypothesis, according to which, a third factor, which in our model represents technology shocks, moves both inflation and the dividend yield in the same direction, resulting in a positive correlation between the two.
\end{abstract}

JEL code: E44, G12

Key words: inflation illusion, dividend yield, inflation

\footnotetext{
${ }^{0}$ I would like to thank Bryan Boulier, Tara Sinclair, Herman Stekler, Thomas Tallarini, and seminar participants at GWU, FDIC, Philadelphia Fed, and University of Maryland at College Park for comments and suggestions. Chao Wei, Department of Economics, George Washington University, 1922 F Street, NW, Washington, DC 20052. Email address: cdwei@gwu.edu; Telephone: (202) 994-2374; Fax: (202) 994-6147.
} 
The empirical relationship between inflation and stock prices has been a subject of enduring interest to academics, investment professionals, and monetary policy makers. The leading practitioner model of equity valuation, the so-called "Fed model", implies that stock yields are highly positively correlated with inflation, a prediction borne out by the empirical evidence presented by Asness (2000, 2003).

Despite the empirical success of the Fed model, it is difficult to justify theoretically why the dividend yield, a real variable, should covary with a nominal variable such as inflation. Three hypotheses have been put forward to explain this positive correlation. The first hypothesis is that, inflation, or the monetary authority's responses to inflation, damages the real economy, and in particular, the profitability of the corporate sector. In this case, the growth rate of real dividends declines in response to inflation, driving up the dividend yield. The second hypothesis is that inflation makes investors more risk averse, driving up the equity premium, and thus the real discount rate. Brandt and Wang (2003) present a model of this sort.

Modigliani and Cohn (1979) propose a third hypothesis: namely inflation illusion. According to their hypothesis, stock market investors fail to understand the effect of inflation on nominal dividend growth rates and extrapolate historical nominal growth rates even in periods of changing inflation. From the perspective of a rational investor, this implies that stock prices are undervalued when inflation is high and overvalued when it is low.

Campbell and Vuolteenaho (2004, henceforth CV) provide strong support for the importance of inflation illusion in explaining the positive association of the dividend yield and inflation. They use a VAR model to decompose the log dividend yield into two components, representing respectively the long-run expected dividend growth and the long-run discount rate, with the later being further decomposed into the subjective risk-premium and the mispricing component driven by inflation illusion. However, due to the unobservability of the long-run discount rate and the subjective risk premium, the mispricing component is a residual, which arises from the regression of the estimated long-run discount rate on a proposed measure of the subjective risk premium. This approach subjects the interpretations of their conclusions to two restrictions: First, the estimation of the long-run discount rate may be sensitive to what state variables are included in the VAR; Second, some part of what is labelled mispricing may be in fact a second component of the 
subjective risk premium, not contained in the measure of risk proposed. As pointed out by Campbell and Ammer (1993), a shortcoming of such a VAR decomposition approach is that the results tend to overstate the importance of whichever component is treated as a residual.

This paper takes a distinctively different approach from CV(2004). We explore an explanation for the positive association between inflation and the dividend yield with no inflation illusion involved. To achieve this goal, we build a dynamic general equilibrium New-Keynesian model to study the relationship between inflation and the dividend yield. In contrast to a VAR framework as in CV (2004), our structural approach achieves internal consistency of business cycle and financial variables in a general equilibrium framework. It thus enables us to study the channels through which fundamental shocks affect both inflation and the dividend yield. Moreover, the VAR structure of our model solutions makes it possible to decompose the dividend yield into the expected long-term dividend growth rate and the discount rate components, so that their relative importance can be studied.

The model results support a proxy hypothesis. According to the hypothesis, a third factor, which in our model represents technology shocks, moves both inflation and the dividend yield in the same direction, resulting in a positive association between the two. In our model, the long-run expected dividend growth covaries with inflation. As result, it is the positive correlation between the long-run real discount rate and inflation which drives the positive association between the dividend yield and inflation. The size of the positive correlation and the relative importance of the long-run expected dividend growth versus discount rates depend upon the structural parameters of the model.

This paper belongs to an expanding literature on the influence of the macroeconomy on the stock market. Fama (1981) advocates a proxy hypothesis to explain the negative relations between inflation and real equity returns. Marshall (1992) incorporates Fama's hypothesis in a monetary endowment economy with transaction costs. Our model differs from this traditional literature in the following aspects. First, in our model the production sector is nontrivial. All the important variables, including consumption, dividends and inflation are endogenously determined. Second, the comovement of inflation and labor compensation in our model affects the deviation of dividends from consumption, an element absent in endowment economies. Third, there has been considerable amount of work on the asset pricing implications of real business cycle models, such as Jermann (1998) and Boldrin, Christiano 
and Fisher (2001). However, the asset pricing implications of New-Keynesian sticky-price models, and in particular, the relationship between inflation and stock prices in such a framework, have not been well studied. This area is particularly interesting given the possible influence of monetary policy rules on these relations. Brandt and Wang (2003) explicitly assume that investors' relative risk aversion increases with inflation. While in our model, it is the third factor, which represents technology shocks, which moves both inflation and the dividend yield in the same direction.

The paper is organized as follows: Section 1 describes a standard NewKeynesian sticky-price model. Section 2 studies the theoretical implications of the model. Section 3 conducts the quantitative analysis and decomposes the dividend yield into the long-run dividend growth and discount rate components. Section 4 concludes.

\section{The Model}

In this section, we describe a standard New-Keynesian model.

\section{$1.1 \quad$ Preferences}

Representative households maximize expected lifetime utility of consumption, subject to a sequential budget constraint:

$$
\max E_{t} \sum_{n=0}^{\infty} \beta^{n}\left[\frac{\left(C_{t+n}-b C_{t+n-1}\right)^{1-\sigma} A_{t+n}^{\sigma}-1}{1-\sigma}-\tau \frac{L_{t+n}^{\theta}}{\theta}+g\left(\frac{M_{t+n}}{P_{t+n}}\right)\right]
$$

such that

$$
C_{t}+\frac{M_{t}}{P_{t}}+f_{t+1}^{\prime} V_{t}^{f}=W_{t} L_{t}+f_{t}^{\prime}\left(V_{t}^{f}+D_{t}^{f}\right)+\frac{M_{t-1}}{P_{t}}+T_{t}
$$

The coefficient $\beta$ is the subjective discount factor, and $C_{t}$ is real consumption at time $t$. The coefficient $\sigma$ measures the curvature of the representative agent's utility function with respect to its argument $C_{t}-b C_{t-1}$, where $b$ measures the habit persistence based on consumption in the previous period. The preference shock $A_{t}$, is an independent normal random variable with its logarithm denoted as $\varepsilon_{a, t}$. The parameter $\tau$ reflects the degree of disutility from working, $L_{t}$ is the labor supply at time $t, \theta$ indexes the degree of 
labor supply elasticity, and $g\left(\frac{M_{t}}{P_{t}}\right)$ represents the utility from holding the real money balance. In the budget constraint, $f_{t+1}$ represents the vector of financial assets held at period $t+1$ and chosen at $t$, including the nominal bond; and $V_{t}^{f}$ and $D_{t}^{f}$ are vectors of asset prices and current period payouts, respectively; $W_{t}$ represents the real wage, and $T_{t}$ is the money injected in period $t$ in a lump sum fashion.

The first-order conditions for consumption/saving, labor supply and money holdings are $^{1}$ :

$$
\begin{aligned}
E_{t}\left[\beta \frac{\Psi_{t+1}}{\Psi_{t}} \frac{\left(1+R_{t}\right)}{P_{t+1} / P_{t}}\right] & =1, \\
\Psi_{t} & =\left(C_{t}-b C_{t-1}\right)^{-\sigma} A_{t}^{\sigma}, \\
W_{t} & =\tau \frac{L_{t}^{\theta-1}}{\Psi_{t}},
\end{aligned}
$$

where $\Psi_{t}, P_{t}$ and $R_{t}$ represent respectively the marginal utility of consumption, the aggregate price level and the nominal interest rate. Denote $\psi_{t}$ as the log-linearized deviation of the marginal utility of consumption from its steady state value:

$$
\psi_{t}=-\frac{\sigma}{1-b} c_{t}+\frac{\sigma b}{1-b} c_{t-1}+\sigma \varepsilon_{a, t} .
$$

From now on, all lower case letters represent log-linearized deviations of corresponding variables from their steady state values.

\subsection{Production Technology and Price-Setting}

We follow Bernanke, Gertler and Gilchrist (1998) in assuming a wholesale sector for production and a retail sector for pricing.

\subsubsection{Wholesale Sector}

Competitive firms produce wholesale goods, make decisions on how much output to produce and how much to invest.

\footnotetext{
${ }^{1}$ The money demand equation serves only to determine how much money the central bank needs to supply to clear markets given its interest rate target. This equation can be dropped when a monetary policy rule is present.
} 
Production Technology of Wholesale Sector Wholesale goods are produced using the following technology:

$$
Y_{w, t}=Z_{t} K_{t}^{1-\alpha} L_{t}^{\alpha},
$$

where the logarithm of the technology shock, $Z_{t}$, follows an AR1 process:

$$
z_{t}=\rho z_{t-1}+\varepsilon_{z, t}, \text { where } \varepsilon_{z, t} \sim N\left(0, \sigma_{z}^{2}\right), 0<\rho<1 .
$$

The wholesale firms choose labor input optimally to maximize their profits. The maximization condition shows that the relative price of wholesale goods is equal to the real wage over the marginal product of labor. Define $\mu_{t}$ such that

$$
\exp \left(\mu_{t}\right)=\frac{P_{w, t}}{P_{t}}=\frac{W_{t}}{M P L_{t}} .
$$

Log-linearizing the above equation and substituting in equations (5) and (7) yields ${ }^{1}$ :

$$
\mu_{t}=\frac{\theta-\alpha}{\alpha} y_{t}-\frac{\theta}{\alpha} z_{t}-\frac{\theta(1-\alpha)}{\alpha} k_{t}-\psi_{t} .
$$

Investment Decisions Wholesale firms make investment decisions given the above production technology. We assume convex adjustment costs in the investment technology ${ }^{2}$. Namely,

$$
K_{t+1}=(1-\delta) K_{t}+\phi\left(\frac{I_{t}}{K_{t}}\right) K_{t},
$$

where

$$
\phi\left(\frac{I_{t}}{K_{t}}\right)=\frac{\delta^{\eta}}{1-\eta}\left(\frac{I_{t}}{K_{t}}\right)^{1-\eta}+\frac{\eta \delta}{\eta-1} .
$$

The parameter $\eta$ measures the adjustment cost. When $\eta$ approaches 0 , adjustment cost is zero. The investment adjustment cost is infinite when $\eta$ goes to infinity.

\footnotetext{
${ }^{1}$ Although the output of wholesale goods, $Y_{w, t}$, is different from the aggregate output $Y_{t}$, they are the same in the log-linearized first order approximation, as demonstrated in Christiano, Eichenbaum and Evans (2001). We denote their log-linearized deviations from the steady state output as $y_{t}$.

${ }^{2}$ The specification of covex adjustment cost is similar to Jermann (1998) and Boldrin, Christiano and Fisher (2001).
} 
The maximization problem facing the wholesale firms is:

$$
\max _{I_{t}} \sum_{n=0}^{\infty} E_{t}\left\{\beta^{n} \frac{\Psi_{t+n}}{\Psi_{t}}\left[\frac{P_{w, t+n}}{P_{t+n}} Y_{w, t+n}-W_{t+n} L_{t+n}-I_{t+n}\right]\right\} .
$$

Log-linearizing the first-order condition for investment yields:

$$
\begin{aligned}
\eta\left(i_{t}-k_{t}\right)= & E_{t}\left(\psi_{t+1}-\psi_{t}\right)+[1-\beta(1-\delta)]\left(\mu_{t+1}+y_{t+1}-k_{t+1}\right) \\
& +\beta \eta E_{t}\left(i_{t+1}-k_{t+1}\right)
\end{aligned}
$$

\subsubsection{Pricing Decisions of Retail Sector}

We assume that there exists a continuum of retailers of measure one. Retailers buy wholesale goods in a competitive market and differentiate these goods at no resource cost. Households and wholesale firms then purchase CES aggregates of these retail goods. Profits from retail activity are rebated lump-sum to households.

Let $Y_{j, t}$ be the quantity of output sold by retailer $j$, measured in units of wholesale goods, and let $P_{j, t}$ be the nominal price. Total final goods, $Y_{t}$, are the following composite of individual retail goods:

$$
Y_{t}=\left[\int_{0}^{1} Y_{j, t}^{\gamma} d j\right]^{\frac{1}{\gamma}}
$$

where $0<\gamma<1$.

The corresponding price index, $P_{t}$, is given by

$$
P_{t}=\left[\int_{0}^{1} P_{j, t}^{\frac{\gamma}{\gamma-1}} d j\right]^{\frac{\gamma-1}{\gamma}}
$$

Final goods are then sold to households and the wholesale production sector for consumption and investment. The economy-wide resource constraint is given by

$$
Y_{t}=C_{t}+I_{t}
$$

Given the index (10), the demand facing each retailer is given by

$$
Y_{j, t}=\left(\frac{P_{j, t}}{P_{t}}\right)^{\frac{1}{\gamma-1}} Y_{t}
$$


Since retail goods are heterogeneous, retail firms set prices taking the demand curves and the price of wholesale goods as given. We incorporate sticky prices into the model as Calvo (1983). We assume that at each period $\varphi$ fraction of randomly chosen retail firms are free to set prices, while the rest have to set their prices according to $P_{j, t}=\frac{P_{t-1}}{P_{t-2}} P_{j, t-1}$. The pricing decision facing the price setters is ${ }^{3}$ :

$$
\max _{P_{t}^{*}} \sum_{n=0}^{\infty}\left\{(1-\varphi)^{n} E_{t}\left[\beta^{n} \frac{\Psi_{t+n}}{\Psi_{t}}\left(\frac{P_{t}^{*} \Pi_{m=0}^{n-1} \pi_{t+m}-P_{w, t+n}}{P_{t+n}}\right) Y_{j, t+n}^{*}\right]\right\},
$$

where $Y_{j, t+n}^{*}$ is demand for good $j$ given optimally chosen $P_{t}^{*}$.

Defining $\pi_{t}=\ln \left(\frac{P_{t}}{P_{t-1}}\right)$, log-linearizing equation (11) around the nonstochastic steady state and substituting in the optimal price $P_{t}^{*}$ and equation (9), we obtain the Phillips curve:

$$
\pi_{t}=\frac{1}{1+\beta} \pi_{t-1}+\frac{\beta}{1+\beta} E_{t} \pi_{t+1}+\frac{\varphi[1-\beta(1-\varphi)]}{(1+\beta)(1-\varphi)} \mu_{t},
$$

where $\mu_{t}$, as defined in equation (9), is the log-linearized deviation of retailers' real marginal cost from its steady state.

\subsection{Monetary Policy Rule}

We assume that the monetary authority responds to the deviations of inflation and output from their steady state values. In particular, monetary policy is described by the following interest rate reaction function:

$$
R_{t}=\rho_{R} R_{t-1}+\left(1-\rho_{R}\right)\left(1+\rho_{\pi}\right) \pi_{t}+\rho_{y} y_{t}+\varepsilon_{R, t}, \text { where } \varepsilon_{R, t} \sim N\left(0, \sigma_{R}^{2}\right),
$$

where $\rho_{\pi}, \rho_{y}>0$. A positive $\rho_{\pi}$ guarantees that the central bank adjusts the short-term nominal interest rate so that the targeted ex post real interest rate rises when inflation exceeds its target value, which is assumed to be the steady state rate of inflation. A positive $\rho_{y}$ indicates a countercyclical monetary policy.

\footnotetext{
${ }^{3}$ The derivations of the Phillips curve are identical to Christiano, Eichenbaum, and Evans (2001), except that in their model pricing decisions are made one period ahead of the realization of shocks.
} 


\section{Inflation and Stock Prices}

In this section, we use the log-linearization methods to solve the model. The VAR structure of the model solutions makes it possible to decompose the log dividend yield into components related to future dividend growth rates and discount rates.

The model solution can be represented by a loglinear state space system, with the vector of state variables, $\mathbf{s}_{t}$, following a first order autoregressive process with multivariate normal i.i.d impulses:

$$
\mathbf{s}_{t}=\Lambda \mathbf{s}_{t-1}+\mathbf{B} \xi_{t}
$$

where the square matrix $\boldsymbol{\Lambda}$ governs the dynamics of the system ${ }^{4}$, and $\mathbf{B}$ summarizes the covariance structure of the impulses. In the model economy considered here, $\mathbf{s}_{t}$ contains the nominal interest rate $R_{t}$, the inflation rate $\pi_{t}$, consumption $c_{t}$, the aggregate technology shock $z_{t}$, and the capital stock, $k_{t+1}$, which is determined based on information available at time $t$. The vector $\xi_{t}$ contains normalized impulses, namely, $\left\{\frac{\varepsilon_{R, t}}{\sigma_{R}}, \frac{\varepsilon_{z, t}}{\sigma_{z}}, \frac{\varepsilon_{a, t}}{\sigma_{a}}\right\}$, where $\sigma_{a}$ is the standard deviation of $\varepsilon_{a, t}$.

This system provides us with the log of investment, $i_{t}$, the log of dividends, $d_{t}$, and the $\log$ of the marginal utility of consumption, $\psi_{t}$, as linear combinations of $\mathbf{s}_{t-1}$ and $\xi_{t}$. We derive expressions for the log of dividends and the dividend yield below to examine the relationship between inflation and stock prices.

The level of dividends, $D_{t}$, can be written as

$$
D_{t}=C_{t}-W_{t} L_{t}
$$

To derive an expression for the log of dividends, we first recognize that given the Cobb-Douglas structure of the production function, equation (8) implies the following:

$$
\mu_{t}=w_{t}+l_{t}-y_{t}
$$

Substituting the above equation, the Phillips curve and the log-linearized equation (12) into the log-linearized equation (17), we can easily write the

\footnotetext{
${ }^{4}$ We require the system to be stationary. Thus the characteristic roots of $\boldsymbol{\Lambda}$ has modulus less than or equal to 1 .
} 
log-linearized dividend as:

$$
\begin{aligned}
d_{t}= & \frac{\widehat{c}(1-\widehat{c}+\widehat{d})}{\widehat{d}} c_{t}-\frac{(1-\widehat{c})(\widehat{c}-\widehat{d})}{\widehat{d}} i_{t} \\
& -\frac{(\widehat{c}-\widehat{d})}{\widehat{d}} \frac{(1+\beta)(1-\varphi)}{\varphi[1-\beta(1-\varphi)]}\left(\pi_{t}-\frac{1}{1+\beta} \pi_{t-1}-\frac{\beta}{1+\beta} E_{t} \pi_{t+1}\right),
\end{aligned}
$$

where $\widehat{c}$ and $\widehat{d}$ are respectively the steady state ratio of consumption and dividends to output. Substituting the model solutions for consumption, investment and inflation into this equation, the log of dividends can be rewritten as

$$
d_{t}=\mathbf{d}_{A} \mathbf{s}_{t-1}+\mathbf{d}_{B} \xi_{t}
$$

Accordingly, based on equation (6), the log of the marginal utility can be written as

$$
\psi_{t}=\psi_{A} \mathbf{s}_{t-1}+\psi_{B} \xi_{t} .
$$

We proceed further to derive an expression for the dividend yield. We focus on the value of a conglomerate consisting of retail and wholesale firms. This makes sense since both sectors are owned by households. The value of the firm is

$$
V_{t}=E_{t}\left[\beta \frac{\Psi_{t+1}}{\Psi_{t}}\left(D_{t+1}+V_{t+1}\right)\right]
$$

and as a result, the log dividend yield is ${ }^{5}$

$$
d_{t}-v_{t}=-\left(E_{t} \psi_{t+1}-\psi_{t}\right)-\left(E_{t} d_{t+1}-d_{t}\right)+\beta E_{t}\left(d_{t+1}-v_{t+1}\right) .
$$

After substituting the solutions of $d_{t}$ and $\psi_{t}$ into the equation, we can solve for the log dividend yield as

$$
\begin{aligned}
d_{t}-v_{t} & =\widehat{\mathbf{y}}_{A} s_{t-1}+\widehat{\mathbf{y}}_{B} \xi_{t}, \text { where } \\
\widehat{\mathbf{y}}_{A} & =\left(\psi_{A}+\mathbf{d}_{A}\right)(\mathbf{I}-\mathbf{A})(\mathbf{I}-\beta \mathbf{A})^{-1}, \\
\widehat{\mathbf{y}}_{B} & =\left(\psi_{B}+\mathbf{d}_{B}\right)-\left(\psi_{A}+\mathbf{d}_{A}-\beta \widehat{\mathbf{y}}_{A}\right) \mathbf{B} .
\end{aligned}
$$

The log dividend yield can be decomposed to examine the relationship between inflation and the two components, the future dividend growth and

\footnotetext{
${ }^{5}$ By using the log-linearization method to derive the log dividend yield, we abstract from consideration of the time-varying risk premium in this paper.
} 
discount rate. The log-linear dynamic valuation framework of Campbell and Shiller (1988) show that

$$
d_{t}-v_{t}=E_{t} \sum_{j=0}^{\infty} \beta^{j} r_{t+1+j}-E_{t} \sum_{j=0}^{\infty} \beta^{j} \triangle d_{t+1+j}
$$

where $\triangle d$ denotes log dividend growth rate and $r_{t}$ denotes the log stock return. The decomposition says that changes in log dividend yields must be associated with changes in expectations of future dividend growth or real returns. The VAR structure of the model solutions makes it convenient to derive an expression for the second term in the above equation, namely,

$E_{t} \sum_{j=0}^{\infty} \beta^{j} \triangle d_{t+1+j}=\mathbf{d}_{A}\left[(1-\beta)(\mathbf{I}-\beta \mathbf{A})^{-1} \mathbf{A}-\mathbf{I}\right] \mathbf{s}_{t-1}+\left[(1-\beta) \mathbf{d}_{A}(\mathbf{I}-\beta \mathbf{A})^{-1} \mathbf{B}-\mathbf{d}_{B}\right] \xi_{t}$.

The coefficient in the regression of log dividend yields on inflation is:

$$
\beta_{\pi}=\frac{\operatorname{cov}\left(d_{t}-v_{t}, \pi_{t}\right)}{\operatorname{var}\left(\pi_{t}\right)}
$$

which can be further decomposed into the regression coefficients of the two components on inflation:

$$
\beta_{\pi}=\frac{\operatorname{cov}\left(E_{t} \sum_{j=0}^{\infty} \beta^{j} r_{t+1+j}, \pi_{t}\right)}{\operatorname{var}\left(\pi_{t}\right)}-\frac{\operatorname{cov}\left(E_{t} \sum_{j=0}^{\infty} \beta^{j} \triangle d_{t+1+j}, \pi_{t}\right)}{\operatorname{var}\left(\pi_{t}\right)} .
$$

The coefficient $\beta_{\pi}$ can also be decomposed according to the contribution of different exogenous shocks. Due to the moving average terms involved in computing the covariance between the dividend yield and inflation, the decomposition is most effectively done in numerical simulations.

\section{Quantitative Predictions on Inflation and Stock Prices}

The objective of the quantitative evaluation is to examine the model's ability to explain the positive association between the dividend yield and inflation, while maintaining reasonable business cycle implications. The role of deep structural parameters, and in particular, monetary policy parameters, can also be studied in such a quantitative framework. We first start with the calibration of the model. 


\subsection{Calibration}

The model parameters can be categorized into the following three groups:

\subsubsection{Monetary Policy Rule Parameters}

The monetary policy rule is characterized by the set of four parameters, $\left\{\rho_{R}, \rho_{\pi}, \rho_{y}, \sigma_{r}\right\}$. They are respectively set to $\{0.8,0.23,0.1,0.002\}$. These parameter values are conventional in New-Keynesian models. Sensitivity analysis will be carried out to examine the significance of different monetary policy rules on the relation between inflation and stock prices.

\subsubsection{Preference}

The preference-related parameters consist of $\left\{\beta, \sigma, b, \sigma_{a}\right\}$. The subjective time discount rate, $\beta$, is set to $1.03^{-0.25}$, which implies a steady state annualized real interest rate of 3 percent. Each model period is considered as one quarter. We set $\sigma$ to 3 . The parameter $b$, which indexes the degree of habit persistence, is set to 0.9, similar to the value used in Jermann (1998). The parameter $\sigma_{a}$ is set to $1 \times 10^{-3}$.

\subsubsection{Production and Investment}

There are nine production-related parameters: $\left\{\delta, \alpha, \rho, \sigma_{z}, \eta, \gamma, \theta, \varphi, \tau\right\}$. The capital depreciation rate $\delta$ is 0.025 . The constant labor share in a CobbDouglas production function is $\frac{2}{3}$. The persistence parameter of the technology shock is 0.95 , and $\sigma_{z}$ is set to 0.007 , as standard in real business cycle models. The parameter $\eta$ stands for the inverse of the elasticity of the investment capital ratio with respect to Tobin's Q. We set $\eta$ to $\frac{1}{0.23}$, which is the values used in Jermann (1998) and Boldrin, Christiano and Fisher (1999). The parameter $\gamma$ represents the degree of monopolistic competition in the economy. When $\gamma$ approaches 1 , the economy is close to perfect competition. We set $\gamma$ to 0.3 in the benchmark case, and present some sensitivity analysis. The parameter $\theta$, which describes the labor supply elasticity, is set to 2 . The parameter $\varphi$ represents the fraction of firms which cannot set prices for a given period. We set its value to 0.5 . The parameter $\tau$ and the steady state level of capital stock are set so that the consumption-output ratio is 0.75 , and the fraction of labor used for production is 0.3 . 


\subsection{Model Results}

The benchmark model generates reasonable business cycle and asset return statistics, and most importantly, provides a rational explanation for the positive association between inflation and the dividend yield. Table 1 shows the model predictions on the standard deviations and first order autocorrelations of the nominal interest rate, inflation and the dividend yield. The aggregate statistics implied by the model are reasonably close to the data, except for the standard deviation of the log dividend yield. Since the stock prices in our model are entirely determined by fundamentals, it is understandable that the dividend yield is far less volatile than in the data ${ }^{6}$. The model also generates historical consumption and investment volatility relative to that of output.

Table 2 reports the regression coefficients of the dividend yield and its components on inflation implied by the theoretical model. The theoretical model predicts a regression coefficient of the dividend yield on inflation of similar magnitude as their empirical counterpart, which is reported to be 4.01 in CV (2004).

In our model, the long-run growth rate of dividends covaries with inflation. To the extent that high inflation coincides with negative technology shocks, the future dividend growth looks bright due to the low initial dividend level. This explains why the long-run expected dividend growth covaries with inflation in the above regression. It is the comovement of inflation and the long-run risk-free real discount rate which explains the positive correlation between inflation and the dividend yield.

The impulse responses further illustrate the dynamics of the model. Figure 1 plots the impulse responses of both business cycle and financial variables in response to one standard deviation of the three fundamental shocks. In particular, we examine the impulse responses of the nominal interest rate, inflation, consumption, dividends, the marginal utility of consumption, and the dividend yield.

In our model, technology shocks are persistent, while the monetary policy and preference shocks are assumed to be white noises. As a result, the impact of technology shocks on the business cycle and financial variables is far more persistent than the other two types of shocks. The preference shocks lower inflation, and raise the dividend yield, thus generating a negative association between inflation and the dividend yield. The impact of monetary policy

\footnotetext{
${ }^{6}$ The excess volatility puzzle is evident here. However, inflation illusion is not the only explanation for this puzzle.
} 
shocks on inflation and the dividend yield is fairly small and short-lived as compared to that of technology shocks.

By sequentially assigning zero variance to one of the exogenous shocks, we are able to distinguish the importance of each type of exogenous shocks in the regression coefficient $\beta_{\pi}$. There is little positive association between the dividend yield and inflation when the variance of technology shocks is zero. This observation indicates that in our model, technology shocks are the primary forces behind the positive correlation between the dividend yield and inflation.

As shown in Figure 1, inflation declines in response to positive technology shocks, as a result of the decline in the marginal cost. Both consumption and dividends increase in response to positive technology shocks. However, the increase in the firm value, mainly initiated by the decline in the marginal utility of consumption, dominates the increase in dividends, resulting in declines in the dividend yield in response to positive technology shocks.

To see this point more clearly, we consider the case when $\beta$ approaches 1 . In this case, equations (20) to (22) imply that $d_{t}-v_{t} \rightarrow d_{t}+\psi_{t}$, or equivalently the $\log$-linearized firm value $v_{t}$ approaches $-\psi_{t}$. The intuition is clear. The higher $\beta$ is, the discount rate is relatively more important than dividends in determining the firm value.

This approximate relationship also enables us to decompose $\beta_{\pi}$ as:

$$
\beta_{\pi} \approx \frac{\operatorname{cov}\left(d_{t}, \pi_{t}\right)}{\operatorname{var}\left(\pi_{t}\right)}+\frac{\operatorname{cov}\left(\psi_{t}, \pi_{t}\right)}{\operatorname{var}\left(\pi_{t}\right)}
$$

As shown in our benchmark case, typically technology shocks drive the dividend up and inflation down, resulting in a negative covariance between dividends and inflation. In order to obtain a positive relationship between the dividend yield and inflation, the covariance between the marginal utility of consumption and inflation must be a large positive value. In other words, the pricing kernel should be specified such that the covariance between $\psi_{t}$ and $\pi_{t}$ is high. Our regression results show a large regression coefficient of the long-run discount rate on inflation, which is consistent with what we have learned from the impulse responses of the model.

As is evident now, the dividend yield and inflation are positively correlated because they both decline in response to positive technology shocks. This finding is along the same line as Fama's proxy hypothesis. 


\subsection{Sensitivity Analysis}

Table 3 reports results of the sensitivity analysis from varying selected structural parameters. The first column indicates alternative calibrations of a given parameter while keeping others at their benchmark values. Below we discuss sensitivity analysis of selected preference, production and policy rule parameters.

\subsubsection{Preference Parameters}

As shown in equation (6), given the negative correlation between inflation and both the level and growth rate of consumption, the higher $\sigma$ or $b$ is, the higher the positive correlation between the marginal utility of consumption and inflation, the higher the positive association between inflation and the dividend yield. When $\sigma$ is set to 1 , there is little positive association between the dividend yield and inflation. When only $b$ is set to zero, the regression coefficient of the dividend yield on inflation is only slightly smaller than the benchmark case. The results indicate that habit formation per se is not required for desired correlation results. However, allowing for habit formation delivers reasonable relative volatilities of consumption and investment relative to output.

\subsubsection{Production Parameters}

When we set $\rho$, the persistence parameter of technology shocks, to zero, the correlation between inflation and the dividend yield turns negative. Temporary technology shocks have a small transitory impact on the firm value, dividends and inflation, resulting in weak positive correlation between inflation and the dividend yield. When technology shocks are temporary, monetary policy and preference shocks play relatively larger roles. In particular, a onestandard-deviation increase in monetary policy shocks reduces both inflation and the firm value, pushing the dividend yield and inflation toward opposite directions. Persistent technology shocks are essential in obtaining a positive correlation coefficient comparable to the data.

Varying $\eta$, the parameter which governs the investment adjustment cost, does not seriously affect the correlation between inflation and the dividend yield. A higher $\eta$ implies higher adjustment cost, and consequently lower volatility of investment relative to output. 
In the steady state of our model, the labor compensation as a fraction of output is equal to $\alpha \gamma$. Since dividends are equal to consumption minus labor compensation, the log of consumption is closest to that of dividends when $\gamma$ approaches 0 . Since labor compensation often covaries with inflation, the higher $\gamma$ is, the stronger negative correlation between dividend and inflation, as compared with that between consumption and inflation. As a result, higher $\gamma$ leads to lower positive association between the dividend yield and inflation.

\subsubsection{Policy Rule Parameters}

With regard to monetary policy rules, a high $\rho_{\pi}$ represents strong inflationstabilizing stance of the monetary authority. When $\rho_{\pi}$ is set to 0.6 , a higher value than in the benchmark case, inflation declines only slightly in response to positive technology shocks. A stable inflation prevents the relative prices of some firms, in particular, those with sticky nominal prices, from rising too high. As a result, consumption, dividends, and especially the firm value increase more in response to positive technology shocks as compared to the benchmark case. These strong responses can explain the larger value of the regression coefficient of the long-run dividend growth component on inflation. The regression coefficient of the dividend yield on inflation is 8.16, much higher than in the benchmark case.

We further examine the case in which the central bank does not respond to the inflation gap by setting $\rho_{\pi}$ to 0 . In this case, the regression coefficient of the dividend yield on inflation is slightly above zero. In our model, when the changes in inflation are not moderated by the monetary authority, drastically declining inflation can push up the relative prices of goods produced by firms with sticky prices, and possibly reduce the aggregate consumption in the short run. As consumption declines, the real discount rate increases temporarily, in an opposite direction as the movement of inflation. As a result, the correlation between inflation and the dividend yield is barely positive.

A high $\rho_{y}$ represents a strongly countercyclical monetary policy. When $\rho_{y}$ is set to 0.5 , the monetary authorities raises the interest rate aggressively in response to positive deviations of output from its steady state. As a result, inflation declines more in response to positive technology shocks compared to the benchmark case. Dividends increase more due to the resulting reduction in labor cost. Despite an increase in the firm value, the strong increase in dividends leads to smaller decrease in the dividend yield, and consequently, 
smaller positive correlation between the dividend yield and inflation.

\subsubsection{The Three Key Parameters}

The sensitive analysis above indicates three crucial elements for the positive association between inflation and the dividend yield. First, $\sigma$, which represents the curvature of the utility function, should be sufficiently high for the real discount rate, and the resulting dividend yield, to be positively correlated with inflation. Second, the persistence parameter of technology shocks, $\rho$, should be high enough for the impact of technology shocks to dominate that of the monetary and preference shocks. Third, the counter-inflationary measures of the monetary authorities, indexed by $\rho_{\pi}$, should enable the real interest rate to increase sufficiently in response to rising inflation. Absence of any of these three ingredients results in little or slightly negative correlation between inflation and the dividend yield.

\section{Conclusion}

In this paper, we show that the positive association between the dividend yield and inflation, of comparable size to its data counterpart, can be rationalized in a dynamic general equilibrium model with no inflation illusion involved. We find that a third factor, which in our model represents technology shocks, moves both inflation and the dividend yield in the same direction, resulting in a positive association between the two.

We abstract from the time-varying real risk premium due to the use of log-linearization in this paper. The possible positive relation between the

real risk premium and inflation, and its contribution to the positive correlation between inflation and the dividend yield will be pursued in our future research. 


\section{References}

[1] Ammer, John and John Campbell, 1993, What Moves the Stock and Bond Markets? A Variance Decomposition for Long-Term Asset Return, Journal of Finance 48: 3-37.

[2] Asness, Clifford, Stock Versus Bonds: Explaining the Equity Risk Premium, Financial Analysis Journal, March/April 2000, 56(2), pp. 96-113.

[3] Asness, Clifford, Fight the Fed Model: The Relationship Between Future Returns and Stock and Bond Market Yields, Journal of Portfolio Management, Fall 2003, 30(1), pp. 11-24.

[4] Bernanke, Ben, Mark Gertler, and Simon Gilchrist, 1999, The Financial Accelerator in a Quantitative Business Cycle Framework, in Handbook of Macroeconomics, ed. by John Taylor and Michael Woodford. NorthHolland, pp 1341-1393.

[5] Brandt, Michael W. and Wang, Kevin Q, Time-varying Risk Aversion and Unexpected Inflation, Journal of Monetary Economics, 50, 2003, pp. 1457-1498.

[6] Boldrin, Michele, Christiano, Lawrence J. and Jonas Fisher, 2001, Habit Persistence, Asset Returns and the Business Cycle, American Economic Review, 91(1), March, pp. 149-166.

[7] Calvo, Guillermo,1983, Staggered Prices in a Utility Maximizing Framework, Journal of Monetary Economics, 12, pp 383-398.

[8] Campbell, John Y. and Cochrane, John H. By force of Habit: a Consumption-based Explanation of Aggregate Stock Market Behavior, Journal of Political Economy, 1999, 107, pp. 205-251.

[9] Campbell, John Y. and Shiller, Robert J. The Dividend-Price Ratio and Expectations of Future Dividends and Discount Factors, Review of Financial Studies, Autumn 1988, I(3), pp. 195-228.

[10] Campbell, John Y. and Vuolteenaho, Tuomo, Inflation Illusion and Stock Prices, American Economic Review Papers and Proceedings, May 2004 
[11] Campbell, John Y. and Vuolteenaho, Tuomo, Inflation Illusion and Stock Prices, NBER Working Paper 10263, January 2004a.

[12] Christiano, Lawrence, Martin Eichenbaum and Charles Evans, 2001, Nominal Rigidities and the Dynamic Effects of a Shock to Monetary Policy, Working paper.

[13] Clarida, Richard, Jordi Gali and Mark Gertler, 2000, Monetary Policy Rules and Macroeconomic Stability: Evidence and Some Theory, Quarterly Journal of Economics, 147-180.

[14] Fama, Eugene F, Stock Returns, Real Activity, Inflation and Money, American Economic Review 71, pp. 545-565.

[15] Jermann, Urban,1998, Asset Pricing in Production Economies, Journal of Monetary Economics 41, pp 257-275.

[16] Lucas, Robert, E., Jr., 1978, Asset Prices in an Exchange Economy, Econometrica 46, pp 1429-1445.

[17] Modigliani, Franco and Cohn, Richard, Inflation, Rational Valuation, and the Market, Financial Analysts Journal, March/April 1979, 37(3), pp. 24-44.

[18] Rouwenhorst, Geert, 1995, Asset Pricing Implications of Equilibrium Business Cycle Models, in Frontiers of Business Cycle Research, ed. by T.F. Cooley. Princeton University Press, pp 294-330. 
Table 1: Descriptive Statistics

\begin{tabular}{l|ccc|cc}
\hline \hline & $s t d(R)$ & $s t d(\pi)$ & $s t d(d y)$ & $\frac{\sigma_{\triangle C}}{\sigma_{\triangle Y}}$ & $\frac{\sigma_{\triangle I}}{\sigma_{\triangle Y}}$ \\
\hline Benchmark & 3.66 & 3.27 & 0.14 & 0.78 & 2.30 \\
Data & 3.47 & 2.95 & 0.43 & 0.51 & 2.65 \\
\hline & $\operatorname{corr}_{1}(R)$ & $\operatorname{corr}_{1}(\pi)$ & $\operatorname{corr}_{1}(d y)$ & & \\
\hline Benchmark & 0.97 & 0.89 & 0.93 & & \\
Data & 0.97 & 0.65 & 0.86 & & \\
\hline
\end{tabular}

The symbols have the following meaning: $d y$, the demeaned log dividend yield; $\operatorname{corr}_{1}()$, the first order auto-correlation of the corresponding variable; $\frac{\sigma_{\triangle \bullet}}{\sigma_{\triangle Y}}$, the ratio of the standard deviation of quarterly consumption (investment) growth rate over the standard deviation of quarterly output growth rate. Data on nominal interest rates are 3-month treasury bill rates from the Federal Reserve. Data on inflation are computed from the consumer price index for all urban consumers covering all items. The dividend yield is extracted from value-weighted equity returns from CRSP. Business cycle data is from Jermann (1998). Business cycle data is quarterly, and asset return data is annualized and in percetage terms except for the log dividend yield.

Table 2: Regression Results

\begin{tabular}{l|cc}
\hline \hline Dependent Variable & Coefficient on $\pi_{t}$ & $R^{2}$ (percent) \\
\hline$d y_{t}$ & 3.46 & 70 \\
$-E_{t} \sum_{j=0}^{\infty} \beta^{j} \triangle d_{t+1+j}$ & -1.03 & 65 \\
$E_{t} \sum_{j=0}^{\infty} \beta^{j} r_{t+1+j}$ & 4.49 & \\
\hline
\end{tabular}

The table shows the regression coefficients of the dependent variables in the first column on inflation $(\pi)$ and the corresponding regression $R^{2}$ values. The variable $d y_{t}$ represents the demeaned log dividend yield, $E_{t} \sum_{j=0}^{\infty} \beta^{j} \triangle d_{t+1+j}$ is the demeaned long-term dividend growth, and $E_{t} \sum_{j=0}^{\infty} \beta^{j} r_{t+1+j}$ is the demeaned long-term real discount rate. 
Table 3: Sensitivity Analysis

\begin{tabular}{|c|c|c|c|c|}
\hline \multicolumn{2}{|c|}{ Alternative Calibrations } & \multicolumn{3}{|c|}{$\begin{array}{l}\text { Regressions of Dividend Yield's } \\
\text { Component on Inflation }\end{array}$} \\
\hline Category & & $d y_{t}$ & $-E_{t} \sum_{j=0}^{\infty} \beta^{j} \triangle d_{t+1+j}$ & $E_{t} \sum_{j=0}^{\infty} \beta^{j} r_{t+1+j}$ \\
\hline Preference & $\begin{array}{l}\sigma=1 \\
b=0\end{array}$ & $\begin{array}{l}0.79 \\
2.42\end{array}$ & $\begin{array}{l}-1.51 \\
-1.54\end{array}$ & $\begin{array}{l}2.30 \\
3.96\end{array}$ \\
\hline Production & $\begin{array}{l}\rho=0 \\
\eta=10 \\
\gamma=0.9\end{array}$ & $\begin{array}{l}-0.43 \\
3.74 \\
2.01\end{array}$ & $\begin{array}{l}-1.04 \\
-1.15 \\
-2.47\end{array}$ & $\begin{array}{l}0.61 \\
4.89 \\
4.49\end{array}$ \\
\hline Policy & $\begin{array}{l}\rho_{\pi}=0.6 \\
\rho_{\pi}=0 \\
\rho_{y}=0.5\end{array}$ & $\begin{array}{l}8.16 \\
0.07 \\
0.93 \\
\end{array}$ & $\begin{array}{l}-2.24 \\
-0.16 \\
-0.35 \\
\end{array}$ & $\begin{array}{c}10.41 \\
0.23 \\
1.28 \\
\end{array}$ \\
\hline
\end{tabular}

The variable $d y_{t}$ represents the demeaned log dividend yield, $E_{t} \sum_{j=0}^{\infty} \beta^{j} \triangle d_{t+1+j}$ is the demeaned long-term dividend growth, and $E_{t} \sum_{j=0}^{\infty} \beta^{j} r_{t+1+j}$ is the demeaned long-term real discount rate. 
Figure 1: Impulse Responses
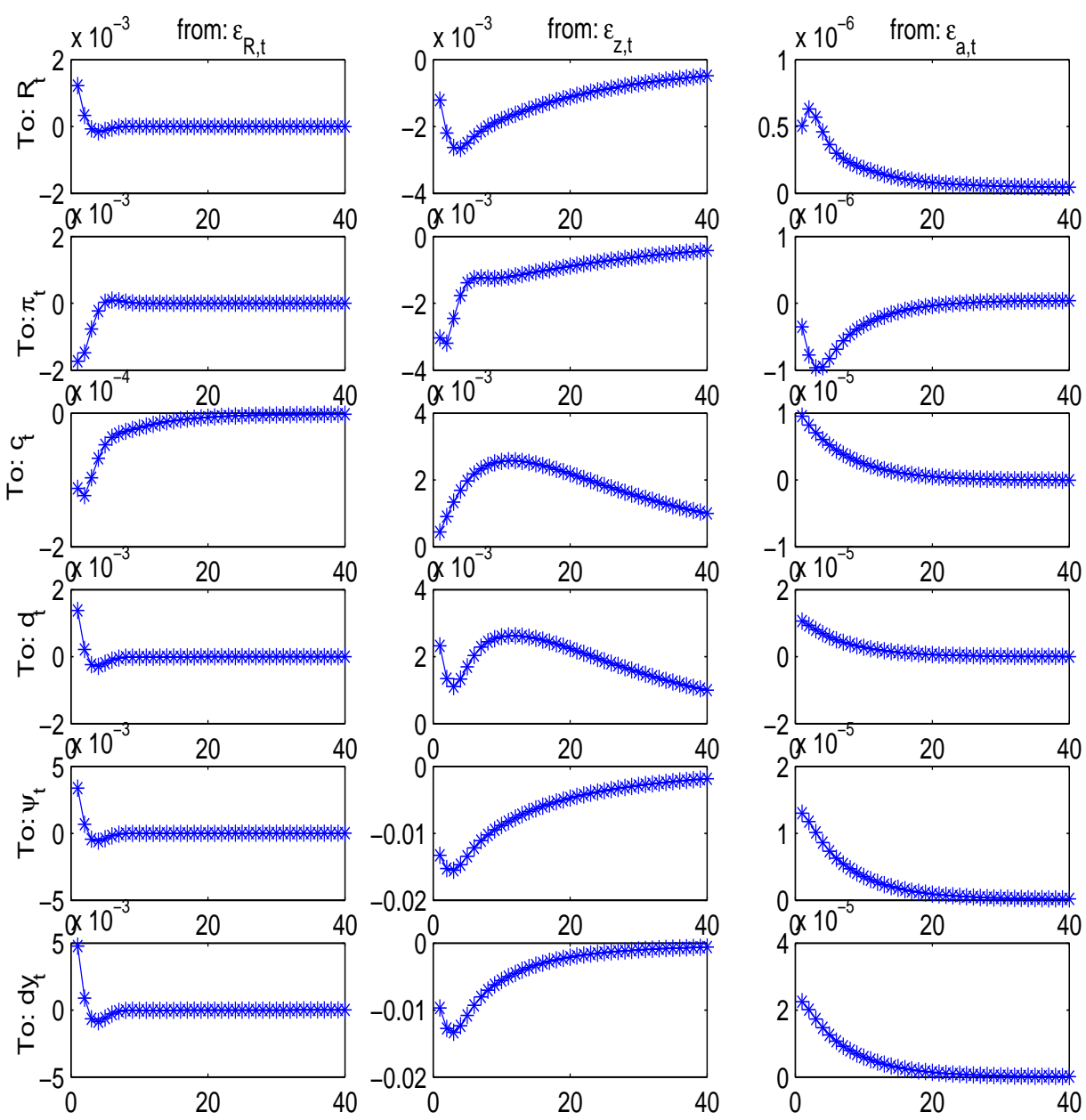